\title{
Effect of Bi non-stoichiometry on the crystallographic structure of $\mathrm{Na}_{1 / 2} \mathrm{Bi}_{1 / 2} \mathrm{TiO}_{3}$
}

\author{
A. Gadelmawla ${ }^{1, \dagger}$, K. Riess ${ }^{1, \dagger}$, M. Hinterstein ${ }^{2}, K^{\prime}$ G. Webber ${ }^{1}$, N. H. Khansur ${ }^{1}$ \\ ${ }^{I}$ Department of Materials Science and Engineering, Friedrich-Alexander-Universität Erlangen-Nürnberg, Erlangen (FAU), Germany, \\ ${ }^{2}$ Karlsruher Institut für Technologie, Institut für Angewandte Materialien, 76131 Karlsruhe, Germany
}

†Equal contributions,ahmed.gadelmawla@fau.de,neamul.khansur@fau.de

Recently, there has been considerable interest in developing high energy density solid-state energy storage systems, where $\mathrm{Na}_{1 / 2} \mathrm{Bi}_{1 / 2} \mathrm{TiO}_{3}$-based materials have also received significant interest for the exceptional large-field electromechanical response. In addition, nonstoichiometric NBT has been reported to be an excellent oxygen-ion conductor. As such, NBT has gained significant interest as the potential new materials for solid-oxide fuel cells and oxygen separation membranes. In this contribution, the effect of Bi non-stoichiometry on the crystal structure has been investigated. $\mathrm{Bi}$ non-stoichiometric $\mathrm{Na}_{0.5} \mathrm{Bi}_{\mathrm{x}} \mathrm{TiO}_{3-\mathrm{y}}$ ceramics with $\mathrm{x}=0.485-0.51$ were prepared by a conventional solid-state reaction method. The chemical analysis of the 4 sintered samples were performed using ICP-OES. The effects of Bi non-stoichiometry on structural transition and ferroelectric stability of NBT ceramics were systematically investigated by the Neutron diffraction at room temperature (RT), in situ high-temperature X-ray diffraction (HTK-XRD up to $560{ }^{\circ} \mathrm{C}$, see Fig. 1), dielectric analyses, and electromechanical measurements. For all compositions, the room temperature structure was found to be rhombohedral $R 3 c$ without secondary phases. Whereas at $250{ }^{\circ} \mathrm{C}$ and $500{ }^{\circ} \mathrm{C}$, tetragonal $P 4 b m$ phase and cubic $P m \overline{3} m$ were observed, respectively. These results are consistent with previous reports. [1-3] In this study, the temperature-dependent phase transition of nonstoichiometric NBT is presented. The changes in the tilt angle $(\omega)$ and octahedral strain $(\xi)$ were calculated from distortion parameters after Megaw and Darlington [4]. An in-depth analysis of the temperature-dependent data shows that the Binonstoichiometry does not alter the average crystallographic structure and phase transition temperatures of the investigated compositions.
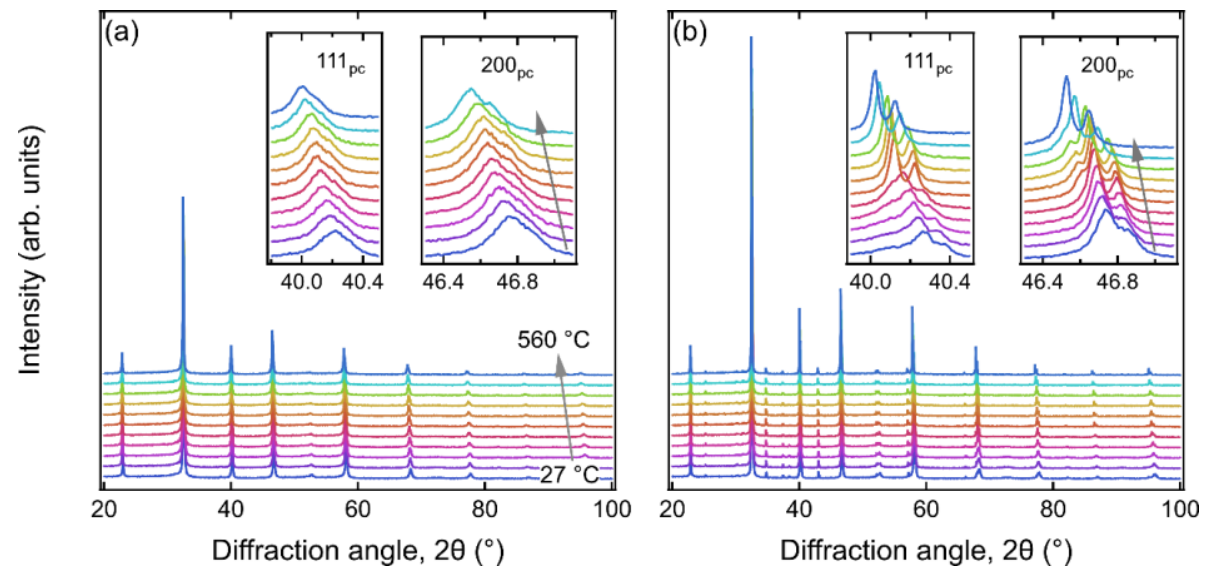

Figure 1. Temperature-dependent XRD data of (a) powder and (b) bulk $\mathrm{NB}_{0.51} \mathrm{~T}$ from $27^{\circ} \mathrm{C}$ (lowest data set) to $560{ }^{\circ} \mathrm{C}$ (top data set).

[1] Vakhrushev, S. B., Isupov, V. A., Kvyatkovsky, B. E., Okuneva, N. M., Pronin, I. P., Smolensky, G. A. \& Syrnikov, P. P. (1985). Ferroelectrics 63 (1), 153-160.

[2] Jones, G. \& Thomas, P. (2002). Acta Crystallogr. Sect. B: Struct. Sci. 58 (2), 168-178.

[3] Jones, G. \& Thomas, P. (2000). Acta Crystallogr. Sect. B: Struct. Sci. 56 (3), 426-430.

[4] Megaw, H. D. \& Darlington, C. N. W. (1975). Acta Crystallographica A 31 (2), 161-173.

Keywords: Ferroelectrics; $\mathrm{Na}_{0.5} \mathrm{Bi}_{0.5} \mathrm{TiO}_{3}$; in situ HTK-XRD; Perovskite. 